\title{
Endovascular treatment of lower extremity arteries is associated with an improved outcome in diabetic patients affected by intermittent claudication
}

Giuseppe Giugliano ${ }^{1}$, Cinzia Perrino ${ }^{1}$, Vittorio Schiano ${ }^{1}$, Linda Brevetti ${ }^{1}$, Anna Sannino ${ }^{1}$, Gabriele Giacomo Schiattarella', Giuseppe Gargiulo', Federica Serino', Marco Ferrone1, Fernando Scudiero', Andreina Carbone ${ }^{1}$, Antonio Bruno ${ }^{1}$, Bruno Amato², Bruno Trimarco ${ }^{1}$, Giovanni Esposito ${ }^{1 *}$

From XXV National Congress of the Italian Society of Geriatric Surgery

Padova, Italy. 10-11 May 2012

\begin{abstract}
Background: Lower extremity peripheral arterial disease (LE-PAD) is a highly prevalent condition among diabetic patients, associated with reduced walking capacity and a high incidence of cardiovascular events. Endovascular revascularization of lower extremities arteries improves walking performance and quality of life of diabetic patients affected by intermittent claudication, but few studies evaluated the impact of revascularization on cardiovascular outcome in this high-risk population. Accordingly, in the present study we evaluated if leg-ischemia resolution by effective lower limbs percutaneous revascularization can also impact cardiovascular outcome in a homogeneous group of diabetic patients affected by intermittent claudication.
\end{abstract}

Methods: 236 diabetic patients affected by LE-PAD at stage II of Fontaine's classification, with ankle/brachial index $\leq 0.90$ and one or more hemodynamically significant stenosis in at least one artery of the ileo-femoro-popliteal axis were enrolled in the study. According to the Trans-Atlantic Inter Society Consensus II recommendations, 123 (52.1\%) underwent percutaneous transluminal angioplasty (PTA group), while 113 (47.9\%) underwent conservative medical therapy only (MT group). The incidence of major cardiovascular events (cardiovascular death, myocardial infarction, ischemic stroke, coronary or carotid revascularization) was prospectively analyzed with Kaplan-Meier curves and the risk of developing a cardiovascular event calculated by Cox analyses.

Results: No baseline difference in cardiovascular risk factors were observed between the PTA and MT groups, except for a lower prevalence of males in PTA group $(74.8 \%$ vs. $85.8 \%, p=0.034)$. Furthermore, patients in the PTA group showed a worse walking capacity as expressed by maximum walking distance (108.7 \pm 300.9 vs $378.4 \pm$ 552.3 meters, $\mathrm{p}<0.001)$. During a median follow-up of 20 months (12.0-29.0), the incidence of cardiovascular events was markedly lower in patients in the PTA group with respect to patients in the MT group $(7.3 \%$ vs. $22.1 \%$, $p=0.001$ ), and patients of the MT group had at Cox analysis a 3.9 increased risk with respect to PTA group, after adjustment for potential confounding factors (95\% Cl 1.1-15.3, p=0.049).

Conclusions: The present study shows that lower limbs revascularization of diabetic patients affected by intermittent claudication, in addition to improve walking performance, is associated with a reduction in the incidence of future major cardiovascular events.

\footnotetext{
* Correspondence: espogiov@unina.it

'Department of Clinical Medicine and Cardiovascular and Immunological

Sciences, "Federico II" University", via Pansini 5, 80131, Naples, Italy

Full list of author information is available at the end of the article
} 


\section{Background}

Cardiovascular disease (CVD) represents the leading cause of death in western countries affecting especially middle-age people [1-3]. One of the most important risk factor, widely recognized as an independent predictor of outcome, is diabetes $[4,5]$. Diabetes affects nearly all vascular beds and in affected patients the risk of morbidity is about twice that of age-matched non diabetic patients [6]. The metabolic disorders accompanying diabetes seem to accelerate the progression of atherosclerosis and indeed more than half of diabetics will die as a result of a cardiovascular ischemic event $[7,8]$.

Lower extremity peripheral arterial disease (LE-PAD), one of the main expressions of atherosclerosis, is a highly prevalent pathological condition among diabetic patients associated with reduced walking capacity and a high incidence of developing future cardiovascular ischemic events [9-14]. When LE-PAD develops in the setting of diabetes, it portends a significantly increased danger to both life and limb function $[15,16]$.

While revascularization should be attempted without delay in all patients presenting with critical limb ischemia, whenever technically possible, the management of intermittent claudication varies depending on the severity of walking impairment and the associated impact of this functional disability on individual lifestyle [17]. According to the most recent guidelines, LE-PAD patients with limited walking capacity should be managed with limb revascularization procedures only when exercise and/or drug therapy fail to improve symptoms [17-23]. Both open repair/bypass surgery or percutaneous trans-luminal angioplasty (PTA) are effective revascularization approaches, and the choice is based upon the number, length and localization of the stenosis/ occlusion, surgery risk score and patient preference $[3,18]$. PTA of the lower limbs is effective in improving not only functional status and quality of life in claudicants, [21,23] but it is also associated with improved cardiovascular outcome [9]. Whether these effects can be also observed in patients with diabetes and intermittent claudication is currently unknown. Thus, we conducted a prospective study to evaluate whether effective endovascular revascularization by PTA might be associated with a reduction in cardiovascular events compared to medical therapy only in a homogeneous cohort of diabetic patients affected by LE-PAD and intermittent claudication.

\section{MethodsE \\ Study population}

Consecutive diabetic patients referred to our vascular laboratory for suspected intermittent claudication were screened for enrollment in this study. Criteria for study entry were all of the following: 1) diagnosis of diabetes mellitus; 2) LE-PAD at stage II of Fontaine's classification (intermittent claudication); 2) $\mathrm{ABI} \leq 0.90$; 3 ) one or more hemodynamically significant stenosis in at least one artery of the ileo-femoro-popliteal axis at B-mode ultrasound. Exclusion criteria were: 1) critical limb ischemia; 2) previous lower limb revascularization; 3 ) recent acute coronary or cerebrovascular ischemic events (6 months); 4) recent coronary or carotid revascularization procedures (6 months); 5) abnormal myocardial ischemia stress test at enrollment; 6) de-compensated heart failure; 7) malignant neoplasia or significant hepatic, renal, or inflammatory disease.

According to the inclusion/exclusion criteria, 252 consecutive diabetic patients affected by intermittent claudication were selected. All patients were treated with maximal medical therapy and encouraged to engage regular physical exercise for at least three months. After this time, patients complaining a severe disability caused by claudication, unable to perform normal work or with very serious impairment of daily life activities despite maximal medical therapy and regular physical exercise $(n=139)$ were selected for angiography and eventually revascularization, while the remaining 113 patients were managed with medical therapy only (MT group). Among the patients initially selected for revascularization, 2 patients refused to undergo angiography, and were excluded from the study. Based on the angiograms, 12 patients displaying TASC D lesions were excluded from the study, while 125 underwent endovascular revascularization. Following PTA, only 123 patients displayed a successful angiographic result (2 patients showed a residual stenosis $>30 \%$ ), and therefore were included in the study (PTA group). All participants gave written informed consent to the study, which was approved by our institutional ethics committee.

\section{Clinical assessment}

In each patient, clinical history and risk factors were assessed at first visit. Smokers included current and former smokers. Hypertension was diagnosed if systolic arterial pressure exceeded $140 \mathrm{mmHg}$ and/or diastolic arterial pressure exceeded $90 \mathrm{mmHg}$ on repeated measurements, or if the patient used antihypertensive drugs. Hypercholesterolemia was diagnosed if plasma total cholesterol exceeded $200 \mathrm{mg} / \mathrm{dl}$, plasma low-density lipoprotein cholesterol exceeded $130 \mathrm{mg} / \mathrm{dl}$, or if the patient used lipid-lowering drugs because of a history of hypercholesterolemia. Hospital records documented previous cardiovascular events.

\section{$A B I$ and maximum walking distance assessment}

ABI was measured at the first visit after participants had rested supine for 5 minutes. The systolic blood pressure in both brachial arteries and the ankle systolic blood pressure for the right and left posterior tibial and dorsalis 
pedis arteries were measured using a Doppler probe. The ABI for each leg was then determined using the higher of the two readings from either the posterior tibial or dorsalis pedis arteries, and the higher of the two brachial readings. The lower ABI of the two legs was used for diagnostic purposes and as predictor of future cardiovascular events. Maximum walking distance (MWD) was tested by treadmill (speed $3 \mathrm{~km} / \mathrm{h}$, inclination 10\%) at the first visit.

\section{Endovascular procedure}

Percutaneous Transluminal Angioplasty (PTA) was performed after diagnostic angiography and intra-venous injection of $70 \mathrm{U} / \mathrm{kg}$ of unfractionated heparin. Bailout nitinol self-expanding stent implantation was performed when a suboptimal angiographic result was obtained. Successful angioplasty was defined by a final angiogram with residual stenosis $<30 \%$.

\section{Assessment of cardiovascular events}

Patients underwent regular follow-up clinical examinations at our Institution at 3-month intervals. The occurrence of cardiovascular death, myocardial infarction, ischemic stroke and coronary or carotid revascularizations was prospectively assessed. Cardiovascular deaths comprised fatal myocardial infarction, fatal stroke, sudden death, and death secondary to arrhythmia or refractory heart failure. The minimum follow-up period was 6 months. Medical records and death certificates of all patients who had an event were obtained and validated by a physician unaware of patient's peripheral treatment. For patients who had more than 1 event, only the first was considered in the analysis.

\section{Statistical analysis}

Statistical analyses were performed using SPSS 16.0 (SPSS, Inc., Chicago, IL, USA). Variables were expressed as absolute numbers and percentage or mean $\pm \mathrm{SD}$, with the exception of leukocyte count that was expressed as median and inter-quartile range because of its skewed distribution. Comparisons were made by t-test for unpaired samples, $\chi^{2}$ test, or Mann-Whitney $\mathrm{U}$ test, as appropriate. Cumulative event rates in the PTA vs. MT group were estimated by Kaplan-Meier curves and probability values by log-rank test.

Cox proportional hazard analyses were performed to verify if endovascular treatment was associated with a lower incidence of future cardiovascular events. The following covariates, known to be potential contributors of cardiovascular risk, were included in the adjusted model: age, sex, smoking, hypercholesterolemia, hypertension, baseline ABI, baseline maximum walking distance, and leukocyte count.

All statistical tests were two-sided. For all tests, a p-value $<0.05$ was considered statistically significant.

\section{Results}

Patients' characteristics

Table 1 reports the baseline characteristics of the patients in the PTA and MT groups. There were fewer males in the PTA group with respect to MT group $(74.8 \%$ vs. $85.8 \%, \mathrm{p}=0.034$ ) and, not surprisingly, the MT group was characterized by a better functional capacity (maximum walking distance: $378.4 \pm 552.3$ vs. $108.7 \pm 300.9$ meters, $\mathrm{p}<0.001)$. Conversely, no difference between the two groups was observed with respect to the prevalence of classic cardiovascular risk factors, cardiovascular comorbidity, and baseline ABI.

\section{Endovascular treatment and outcome}

During a median follow-up of 20.0 months (interquartile range 12.0 - 29.0), 34 of the 236 patients $(14.4 \%)$ had a major cardiovascular event, of which 25 (22.1\%) occurred in the MT group, while only 9 (7.3\%) occurred in the PTA group $(\mathrm{p}<0.001)$. Importantly, the PTA group was characterized by a lower rate of cardiovascular deaths, especially driven by a reduction in the rate of fatal MI (data not shown). Consistent with these results, Kaplan-Meier curves depicting the incidence during follow-up of total cardiovascular events showed a significant advantage in the PTA group vs. MT group (Figure 1).

At Cox analysis, patients in the MT group had a 2.68fold increased risk (95\% CI 1.24-5.74, p = 0.011) of developing a cardiovascular event with respect to patients in the PTA group. Notably, this association remained statistically significant after adjustment for the

Table 1 Baseline characteristics of the study population

\begin{tabular}{llll}
\hline & $\begin{array}{l}\text { PTA Group } \\
\text { (n = 123) }\end{array}$ & $\begin{array}{l}\text { MT Group } \\
\text { (n= 113) }\end{array}$ & $\mathbf{p}$ \\
\hline Age (yr) & $64.7 \pm 9.7$ & $66.2 \pm 8.9$ & 0.323 \\
Males & $92(74.8)$ & $97(85.8)$ & 0.034 \\
Risk factors & & & \\
Hypercholesterolemia & $98(79.6)$ & $79(69.9)$ & 0.152 \\
Hypertension & $112(91.0)$ & $183(92.0)$ & 0.757 \\
Smoking & $107(87.0)$ & $91(80.5)$ & 0.239 \\
BMI & $27.6 \pm 5.3$ & $26.5 \pm 5.2$ & 0.831 \\
LE-PAD severity & & & \\
ABI & $0.66 \pm 0.18$ & $0.65 \pm 0.17$ & 0.580 \\
MWD (meters) & $108.7 \pm 300.9$ & $378.4 \pm 552.3$ & 0.001 \\
Comorbidity & & & \\
Previous Ml & $32(26.0)$ & $33(29.2)$ & 0.584 \\
Previous stroke & $3(2.4)$ & $1(0.9)$ & 0.360 \\
Inflammatory status & & & \\
Leukocyte count $\left(\times 10^{9} / \mathrm{L}\right)$ & $7.9[6.6-9.3]$ & $7.4[5.9-9.1]$ & 0.150 \\
\hline
\end{tabular}

Values are $\mathrm{n}(\%)$ or mean \pm SD or median [interquartile range].

PTA = percutaneous transluminal angioplasty; $\mathrm{MT}=$ medical therapy; $\mathrm{BMI}=$ body mass index; $L E-P A D=$ lower extremity peripheral arterial disease; $A B I=$ ankle/ brachial index; $M W D=$ maximum walking distance; $\mathrm{MI}=$ myocardial infarction . 


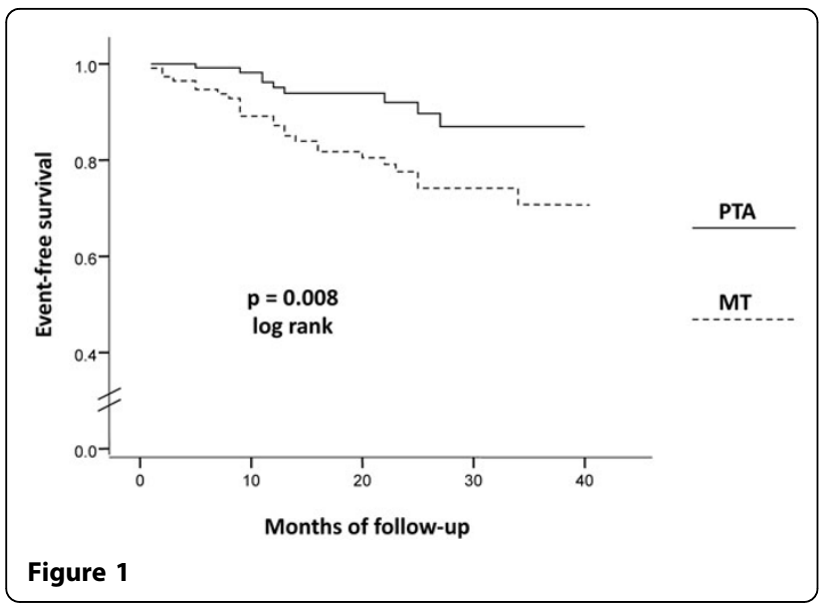

potential confounders indicated above (adjusted $\mathrm{HR}=$ 3.92, $95 \%$ CI 1.10-15.30, $\mathrm{p}=0.049$ ).

\section{Discussion}

The present study demonstrates that successful revascularization of lower extremity arteries in diabetic patients affected by intermittent claudication is associated with a reduction in the incidence of major cardiovascular events. Notably, this association remains unaltered after accounting for possible confounders such as classic cardiovascular risk factors, previous myocardial infarction or stroke, maximum walking distance, leukocyte count and $\mathrm{ABI}$, to date the most powerful prognostic indicator in LE-PAD $[24,25]$. These results might have important clinical implications, and might open a new scenario for diabetic patients affected by intermittent claudication, in which the indications to perform lower-extremity revascularization might be extended to the improvement of global cardiovascular outcome. At this regard, it is also important to emphasize that PTA of the lower limbs is now a safe and largely effective procedure $[18,26]$.

Although patients undergoing PTA were characterized by worse baseline functional capacity compared to the MT group (Table 1), we observed a better cardiovascular outcome in patients undergoing lower extremity reperfusion strategy. Different mechanisms might be accounted for these beneficial effects associated to the revascularization of the ischemic leg. Firstly, PTA increases walking capacity $[20,22]$, and such improvement in functional status induced by PTA might be responsible, at least in part, of the reduction of cardiovascular risk observed in our patients. Indeed, patients affected by intermittent claudication may be severely limited in their occupational and leisure-time physical activity $[27,28]$ and a sedentary lifestyle is a risk factor for adverse cardiovascular events [29-31]. Another possible mechanism for the favourable effects observed in the PTA group might be inherent to the increase of ABI. Indeed, successful revascularization of lower extremities has been shown to improve the ABI, which is the most powerful prognostic indicator in LEPAD patients $[24,25]$. Furthermore, PTA of the lower limbs has been also associated with the improvement of endothelial function [32], which plays an important role in the pathophysiology and natural history of lower extremities atherosclerotic disease [33], and may reduce the ischemia-reperfusion injury which promotes systemic inflammation [34]. At this regard, it is important to emphasize that an increased inflammatory status has been associated to the development and subsequent worsening of atherosclerosis including thrombotic complications, and that the elevation in circulating inflammatory markers increases the risk if ischemic cardiovascular events in LE-PAD [13].

\section{Conclusions}

In conclusion, the present study provides evidence that effective lower limb revascularization by PTA in diabetic patients affected by intermittent claudication not only ameliorates functional status and alleviates symptoms, but is also associated with an improvement of cardiovascular outcome. Further studies are needed to understand the possible mechanisms underlying this result.

\section{List of abbreviations}

CVD: Cardiovascular Disease; LE-PAD: Lower Extremity Peripheral Arterial Disease; PTA: percutaneous trans-luminal angioplasty; TASC: Trans-Atlantic Inter-Society Consensus; ABI: Ankle/Brachial Index.

\section{Acknowledgements}

This article has been published as part of BMC Surgery Volume 12 Supplement 1, 2012: Selected articles from the XXV National Congress of the Italian Society of Geriatric Surgery. The full contents of the supplement are available online at http://www.biomedcentral.com/bmcsurg/supplements/12/ S1.

\section{Author details}

${ }^{1}$ Department of Clinical Medicine and Cardiovascular and Immunological Sciences, "Federico II" University", via Pansini 5, 80131, Naples, Italy.

${ }^{2}$ Department of General, Geriatric, Oncologic Surgery and Advanced Technologies, "Federico II" University", via Pansini 5, 80131, Naples, Italy.

\section{Authors' contributions}

$\mathrm{GG}, \mathrm{CP}, \mathrm{VS}, \mathrm{LB}, \mathrm{AS}, \mathrm{GGS}, \mathrm{GG}, \mathrm{FS}, \mathrm{MF}, \mathrm{FS}, \mathrm{AC}$, AB: conception and design, interpetration of data, given final approval of the version to be published; BA, BT: critical revision, interpretation of data, given final approval of the version to be published; GE: conception and design, critical revision, given final approval of the version to be published.

\section{Competing interests}

The authors declare that they have no competing interests.

Published: 15 November 2012

\section{References}

1. Morrow DA, Braunwald E, Bonaca MP, Ameriso SF, Dalby AJ, Fish MP, Fox KA, Lipka LJ, Liu X, Nicolau JC, et al: Vorapaxar in the secondary prevention of atherothrombotic events. N Engl J Med 2012, 366:1404-1413.

2. Cassese S, Esposito G, Mauro C, Varbella F, Carraturo A, Montinaro A, Cirillo P, Galasso G, Rapacciuolo A, Piscione F: MGUard versus bAre-metal 
stents plus manual thRombectomy in ST-elevation myocarDial infarction pAtieNts-(GUARDIAN) trial: study design and rationale. Catheterization and cardiovascular interventions: official journal of the Society for Cardiac Angiography \& Interventions 2012, 79:1118-1126.

3. Amato B, Iuliano GP, Markabauoi AK, Piscitelli V, Masone S, Compagna R, Esposito G, Piscione F: Endovascular procedures in critical leg ischemia of elderly patients. Acta bio-medica : Atenei Parmensis 2005, 76(Suppl 1):11-15.

4. Perrino C, Scudiero L, Petretta MP, Schiattarella GG, De Laurentis M, llardi F, Magliulo F, Carotenuto G, Esposito G: Total occlusion of the abdominal aorta in a patient with renal failure and refractory hypertension: a case report. Monaldi archives for chest disease = Archivio Monaldi per le malattie del torace $/$ Fondazione clinica del lavoro, IRCCS [and] Istituto di clinica tisiologica e malattie apparato respiratorio, Universita di Napoli, Secondo ateneo 2011, 76:43-46.

5. Esposito G, Cassese S, Gargiulo G, Sannino A, Schiattarella GG, Piscione F, Chiariello M: Balancing hemorrhagic and thrombotic complications in a patient with a very late paclitaxel-eluting stent thrombosis: a clinical case report. J Cardiovasc Med (Hagerstown) 2011, 12:366-369.

6. Vamos EP, Harris M, Millett C, Pape UJ, Khunti K, Curcin V, Molokhia M, Majeed A: Association of systolic and diastolic blood pressure and all cause mortality in people with newly diagnosed type 2 diabetes: retrospective cohort study. BMJ 2012, 345:E5567.

7. Marciano C, Galderisi M, Gargiulo P, Acampa W, D'Amore C, Esposito R, Capasso E, Savarese G, Casaretti L, Lo ludice F, et al: Effects of type 2 diabetes mellitus on coronary microvascular function and myocardial perfusion in patients without obstructive coronary artery disease. European journal of nuclear medicine and molecular imaging 2012, 39:1199-1206.

8. Indolfi C, Torella D, Cavuto L, Davalli AM, Coppola C, Esposito G, Carriero MV, Rapacciuolo A, Di Lorenzo E, Stabile E, et al: Effects of balloon injury on neointimal hyperplasia in streptozotocin-induced diabetes and in hyperinsulinemic nondiabetic pancreatic islet-transplanted rats. Circulation 2001, 103:2980-2986.

9. Giugliano G, Di Serafino L, Perrino C, Schiano V, Laurenzano E, Cassese S, De Laurentis M, Schiattarella GG, Brevetti L, Sannino A, et al: Effects of successful percutaneous lower extremity revascularization on cardiovascular outcome in patients with peripheral arterial disease. International journal of cardiology 2012.

10. Weitz JI, Byrne J, Clagett GP, Farkouh ME, Porter JM, Sackett DL, Strandness DE Jr., Taylor LM: Diagnosis and treatment of chronic arterial insufficiency of the lower extremities: a critical review. Circulation 1996, 94:3026-3049.

11. Meijer WT, Hoes AW, Rutgers D, Bots ML, Hofman A, Grobbee DE: Peripheral arterial disease in the elderly: The Rotterdam Study. Arterioscler Thromb Vasc Biol 1998, 18:185-192.

12. Hirsch AT, Criqui MH, Treat-Jacobson D, Regensteiner JG, Creager MA, Olin JW, Krook SH, Hunninghake DB, Comerota AJ, Walsh ME, et al: Peripheral arterial disease detection, awareness, and treatment in primary care. JAMA 2001, 286:1317-1324.

13. Brevetti G, Giugliano G, Brevetti L, Hiatt WR: Inflammation in peripheral artery disease. Circulation 122:1862-1875.

14. Schiano V, Sirico G, Giugliano G, Laurenzano E, Brevetti L, Perrino C, Brevetti $G$, Esposito G: Femoral plaque echogenicity and cardiovascular risk in claudicants. JACC Cardiovascular imaging 2012, 5:348-357.

15. Bosevski M: Peripheral arterial disease and diabetes. Prilozi / Makedonska akademija na naukite i umetnostite, Oddelenie za bioloski i medicinski nauki = Contributions / Macedonian Academy of Sciences and Arts, Section of Biological and Medical Sciences 2012, 33:65-78.

16. Indolfi C, Stabile E, Perrino C, Chiariello M: Mechanisms of restenosis after angioplasty and approach to therapy (Review). International journal of molecular medicine 1998, 2:143-148.

17. Tendera M, Aboyans V, Bartelink ML, Baumgartner I, Clement D, Collet JP, Cremonesi A, De Carlo M, Erbel R, Fowkes FG, et al: ESC Guidelines on the diagnosis and treatment of peripheral artery diseases: Document covering atherosclerotic disease of extracranial carotid and vertebral, mesenteric, renal, upper and lower extremity arteries: the Task Force on the Diagnosis and Treatment of Peripheral Artery Diseases of the European Society of Cardiology (ESC). European heart journal 2011, 32:2851-2906.

18. Norgren L, Hiatt WR, Dormandy JA, Nehler MR, Harris KA, Fowkes FG: InterSociety Consensus for the Management of Peripheral Arterial Disease (TASC II). J Vasc Surg 2007, 45(Suppl S):S5-67.
19. Criqui MH, Langer RD, Fronek A, Feigelson HS, Klauber MR, McCann TJ, Browner D: Mortality over a period of 10 years in patients with peripheral arterial disease. N Engl J Med 1992, 326:381-386.

20. Rockson SG, Cooke JP: Peripheral arterial insufficiency: mechanisms, natural history, and therapeutic options. Adv Intern Med 1998, 43:253-277.

21. Cook TA, O'Regan M, Galland RB: Quality of life following percutaneous transluminal angioplasty for claudication. Eur J Vasc Endovasc Surg 1996, 11:191-194.

22. Hirsch AT, Haskal ZJ, Hertzer NR, Bakal CW, Creager MA, Halperin JL, Hiratzka LF, Murphy WR, Olin JW, Puschett JB, et al: ACC/AHA 2005 Practice Guidelines for the management of patients with peripheral arterial disease (lower extremity, renal, mesenteric, and abdominal aortic): a collaborative report from the American Association for Vascular Surgery/Society for Vascular Surgery, Society for Cardiovascular Angiography and Interventions, Society for Vascular Medicine and Biology, Society of Interventional Radiology, and the ACC/AHA Task Force on Practice Guidelines (Writing Committee to Develop Guidelines for the Management of Patients With Peripheral Arterial Disease): endorsed by the American Association of Cardiovascular and Pulmonary Rehabilitation; National Heart, Lung, and Blood Institute; Society for Vascular Nursing; TransAtlantic Inter-Society Consensus; and Vascular Disease Foundation. Circulation 2006, 113:e463-654.

23. Keeling AN, Naughton PA, O'Connell A, Lee MJ: Does percutaneous transluminal angioplasty improve quality of life? J Vasc Interv Radiol 2008, 19:169-176.

24. Newman AB, Shemanski L, Manolio TA, Cushman M, Mittelmark M, Polak JF, Powe NR, Siscovick D: Ankle-arm index as a predictor of cardiovascular disease and mortality in the Cardiovascular Health Study. The Cardiovascular Health Study Group. Arterioscler Thromb Vasc Biol 1999, 19:538-545.

25. McKenna $M$, Wolfson $S$, Kuller $L$ : The ratio of ankle and arm arterial pressure as an independent predictor of mortality. Atherosclerosis 1991, 87:119-128.

26. Allaqaband S, Kirvaitis R, Jan F, Bajwa T: Endovascular treatment of peripheral vascular disease. Curr Probl Cardiol 2009, 34:359-476.

27. Breek JC, Hamming JF, De Vries J, Aquarius AE, van Berge Henegouwen DP: Quality of life in patients with intermittent claudication using the World Health Organisation (WHO) questionnaire. Eur J Vasc Endovasc Surg 2001, 21:118-122.

28. iBarletta G, Perna S, Sabba C, Catalano A, O'Boyle C, Brevetti G: Quality of life in patients with intermittent claudication: relationship with laboratory exercise performance. Vasc Med 1996, 1:3-7.

29. Leon AS, Connett J, Jacobs DR Jr., Rauramaa R: Leisure-time physical activity levels and risk of coronary heart disease and death. The Multiple Risk Factor Intervention Trial. JAMA 1987, 258:2388-2395.

30. Pate RR, Pratt M, Blair SN, Haskell WL, Macera CA, Bouchard C, Buchner D, Ettinger W, Heath GW, King AC, et al: Physical activity and public health. A recommendation from the Centers for Disease Control and Prevention and the American College of Sports Medicine. JAMA 1995, 273:402-407.

31. Paffenbarger RS Jr., Hyde RT, Wing AL, Lee IM, Jung DL, Kampert JB: The association of changes in physical-activity level and other lifestyle characteristics with mortality among men. N Engl J Med 1993, 328:538-545.

32. Husmann M, Dorffler-Melly J, Kalka C, Diehm N, Baumgartner I, Silvestro A: Successful lower extremity angioplasty improves brachial artery flowmediated dilation in patients with peripheral arterial disease. $J$ Vasc Surg 2008, 48:1211-1216.

33. Brevetti G, Schiano V, Chiariello M: Endothelial dysfunction: a key to the pathophysiology and natural history of peripheral arterial disease? Atherosclerosis 2008, 197:1-11.

34. Khaira HS, Nash GB, Bahra PS, Sanghera K, Gosling P, Crow AJ, Shearman CP: Thromboxane and neutrophil changes following intermittent claudication suggest ischaemia-reperfusion injury. Eur J Vasc Endovasc Surg 1995, 10:31-35.

doi:10.1186/1471-2482-12-S1-S19

Cite this article as: Giugliano et al.: Endovascular treatment of lower extremity arteries is associated with an improved outcome in diabetic patients affected by intermittent claudication. BMC Surgery 2012 12(Suppl 1):S19. 